\title{
Prevalence of fear of falling, in a sample of elderly adults in the community
}

Danielle Teles da Cruz' Raphaela Ornellas Duque ${ }^{2}$ Isabel Cristina Gonçalves Leite'

\section{Abstract}

Objectives: To investigate the prevalence of fear of falling among a sample of elderly persons in the community, and to analyze its correlation with age, self-perceived health, difficulty walking, use of an assistive device for walking, history of falls, and functional capacity. Method: A cross-sectional study of 314 non-institutionalized elderly individuals, living in the city of Juiz de Fora in the state of Minas Gerais) in 2015, was carried out. A household survey was conducted and fear of falling was assessed using the Falls Efficacy Scale - International - Brazil (FES-I-BR ASIL). The Spearman correlation was used to verify the correlation of the independent variables with the fear of falling. The significance level for the study was $5 \%$. Results: The prevalence of fear of falling among the elderly was $95.2 \%(95 \% \mathrm{CI}=92.3$; 97.3$)$. Fear of falling was significantly correlated with all the variables analyzed: age $(r=0.199)$, self-perceived health $(r=0.299)$, difficulty walking $(\mathrm{r}=-0.480)$, use of an assistive device for walking $(\mathrm{r}=0.337)$, history of falls $(\mathrm{r}=$ $-0.177)$, and functional capacity $(r=-0.476)$. Conclusions: A high prevalence of fear of falling was observed, with a significant correlation between the outcome and the variables studied. These findings point to the need for rehabilitation, prevention, and health promotion strategies that enable healthy aging.

\footnotetext{
Universidade Federal de Juiz de Fora, Faculdade de Medicina, Departamento de Saúde Coletiva, Programa de Pós-Graduação em Saúde. Juiz de Fora, MG, Brasil.

2 Universidade Federal de Juiz de Fora, Faculdade de Fisioterapia, Curso de Fisioterapia. Juiz de Fora, MG,
} Brasil.

Research funding: Conselho Nacional de Desenvolvimento Científico e Tecnológico (National Council for Scientific and Technological Development) (CNPq) and the Ministério da Ciência e Tecnologia (the Ministry of Science and Technology) (MCT). Case No. 480163/2012-0. Universal request for proposal with resources for consumable and permanent materials.

Keywords: Health of the Elderly. Aging. Fear. Accidental Falls.

Cross-Sectional Studies. 


\section{INTRODUCTION}

Population aging is a world-wide phenomenon with developments and impacts that are important for society and for health systems. World Health Organization data indicate that the elderly population in Brazil will rise from its current $12.5 \%$ to approximately $30 \%$ by 2050 . The extent to which this process is occurring in Brazil increases the urgency of understanding the health-related needs of the elderly ${ }^{1}$.

Within this context, fear of falling is recognized as a major public health problem that is commonly found among the elderly, and whose impact has potentially serious outcomes for the lives of these individuals. Included in this analysis are social issues, and increased requirements and costs for healthcare ${ }^{2-4}$. Although the causal mechanisms may not be fully explained, studies indicate that the etiology of fear of falling has a multifactorial nature, involving physical, behavioral, environmental, and functional elements ${ }^{3,5-7}$.

It was believed that the presence of fear of falling was related exclusively to the psychological trauma resulting from experiencing a fall. However, literature shows that it is also present in elderly people who have never fallen ${ }^{6-9}$. Fear of falling is related to low confidence or low self-efficacy in avoiding falls. People with low self-efficacy focus on the obstacles of the task and on their limitations, and avoid situations they consider threatening. Thus, they limit skill development, which results in a basis for constructing fear ${ }^{3,5-7}$.

The aim of this study was to estimate the prevalence of fear of falling among a population of older adults in the community and to analyze its correlation with age, self-perceived health, difficulty walking, use of an assistive device, history of falls, and functional capacity.

\section{METHOD}

This study is part of a broader research project, entitled the Survey on the Health of the Elderly Population of Juiz de Fora, operationalized through two waves of multidimensional population-based household surveys (2010/2011 and 2014/2015). Thus, the present study is a cross-section of the second wave of data collection, with a sample of 214 elderly persons aged 60 years or older who were resident in the northern region of the city of Juiz de Fora, Minas Gerais.

To define the sample calculation at the beginning of the segment in 2010, the national prevalence of elderly persons who had suffered a fall, as indicated by literature $(30 \%)^{10}$, was considered the basis, as this was the principal objective. The study considerations included a desired maximum error of $5 \%$, a $95 \%$ confidence level, correction for finite populations, effect of the sampling design equal to 1.5 (considering the possible effects of stratification and clustering, according to the adopted selection procedure), and possible losses for dropouts $(30 \%)$.

Participants were selected by random sampling, stratified and clustered in multiple stages. The primary sampling units were census tracts. For the random selection, the sectors were grouped into strata defined according to the different health care modalities in which the population of the region was enrolled, subdivided into primary care (Family Health Strategy or traditional), secondary care, or no-coverage area. The selection of these individuals was made using probabilities proportional to their size (resident population according to Census 2000 data), independently in each stratum.

For the second wave of the survey (2014), the sample size calculation was estimated based on the 2010 sample and IBGE data for the 2010 census for the population of the delimited area, at the census tract level of disaggregation, in order to allow resizing of the representative probabilistic sample based on stratification and clustering. To compensate for dropouts from the panel, who were no longer included in the study population, over a timespan of years, the oversample method was used. This allows the initial sampling to be respected, provided that the initial population is known and that the statistical processing, and weights attributed, are different between the groups that make up each panel dropout situation (cases of death, change of address without being able to identify the new address, long term travel, prolonged hospitalization, and entry into a long-term care institution $)^{11}$. Age, sex, and education level were variables selected to delimit the entry of new subjects. The total survey sample included 423 elderly individuals. 
The questionnaire used for the household survey was standardized and pre-tested. The Mini-Mental State Examination (MMSE) was used as a cognitive decline screening tool, which determined whether or not another respondent was needed. In such "other respondent" cases, the questions that depended on the elderly person's perception were not addressed. Individuals who presented behavior in the MMSE suggesting cognitive decline, and who were not accompanied by family members and / or caregivers, were excluded $(\mathrm{N}=23)$.

The sample for this study consisted of elderly persons who participated in the second phase of the Survey on the Health of the Elderly Population of Juiz de Fora and who presented no cognitive decline ( $\mathrm{N}=315)$, excluding those using a wheelchair as a mobility device ( $\mathrm{N}=1$ ) (Figure 1). The intra- and interexaminer agreement found before data collection was substantial or excellent $(>75 \%)$. Throughout the course of the survey, the interviewers were monitored, evaluated, and retrained. For quality control of the information, field supervision was carried out by the principal investigators, and at the end of data collection, roughly $10 \%$ of production was reassessed via another partial interview.

The dependent variable was operationalized with the application of the FES-I BRASIL. This is a scale designed to assess fear of falling based on the definition of low perceived self-efficacy for avoiding falls during regular daily activities ${ }^{5,12}$. The scale includes 16 activities with scores, for each activity, ranging from one to four, in which the lowest score indicates the elderly person is "not at all concerned" with falling and the highest one means the individual is "very concerned" about the possibility of falling. The total scores range from 16 points for individuals without any concern about falling, to 64 points for individuals with extreme concerns ${ }^{5}$.

Functional capacity for the instrumental activities of daily living (IADL) was assessed using the Lawton and Brody Scale. This tool investigates nine instrumental activities: using the phone, shopping, handling finances, preparing one's own meals, cleaning the house, doing household chores, washing clothes, taking medication, and going far from home using any means of transport. The scores range from 9 to 27 points and the lower the score, the greater the degree of dependence. This variable was dichotomized into dependent ( $<18$ points) and independent $(\geq 19 \text { points })^{13}$. The other variables were obtained through a semi-structured questionnaire developed by the researchers.

The significance level was $5 \%$ and the statistical analysis considered the characteristics of the sampling plane. Absolute and relative frequencies were described, as well as the prevalence of the outcome. The variables age, self-perceived health, difficulty walking, use of an assistive device for walking, history of falls, and functional capacity were correlated with the fear of falling variable, calculating the Spearman correlation coefficient. The classification used for correlation was: $<0.49$, weak; 0.50 to 0.69 , moderate; and $\geq 0.70$, strong.

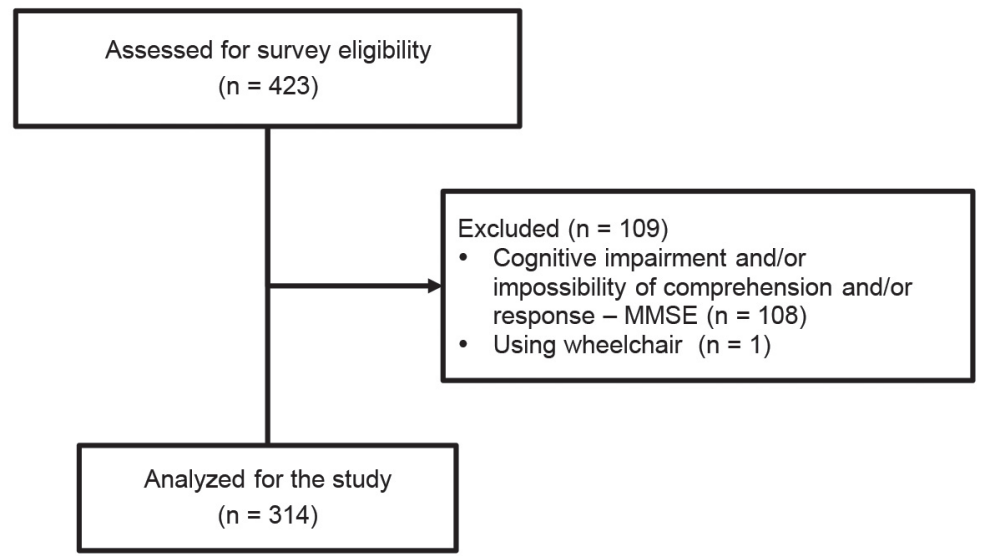

Figure 1. Flowchart of the study sample. Juiz de Fora, MG. 2015. 
The Guidelines and Norms Regulating Research Involving Human Beings were followed, in accordance with the recommendations of Resolution 466/2012 of the National Health Council. The Ethics Committee of the Federal University of Juiz de Fora approved the study (Opinion No. 771/916), which was funded by the National Council for Scientific and $0)$. All the elderly involved on the survey read and signed the free and informed consent form.

\section{RESULTS}

The study included 314 elderly participants. The sample consisted of $62.2 \%$ women, $45.2 \%$ said they were white, $56.1 \%$ were married or living in a stable union relationship, $87.9 \%$ lived with a companion, and $58.6 \%$ belonged to socioeconomic level $\mathrm{C}$. The mean age was 72.7 years (sd \pm 7.32$)$ and education level

was 4.0 years $(\mathrm{sd} \pm 3.50)$. Among the respondents, $74.2 \%$ were Catholic and $96.8 \%$ considered religion important in their lives; 61\% said they had no difficulty walking and $87.3 \%$ said they did not need assistance for mobility. Most (96.5\%) reported using the SUS (Unified Health System), 88.2\% reported some type of morbidity, $53.4 \%$ reported using from 1 to 4 medications, and $56.7 \%$ positively rated their own health. Regarding the history of falls, 34.1\% reported having experienced an episode in the past year ('Table 1).

The prevalence of fear of falling in the study population was $95.2 \%$ (CI 95\%=92.3-97.3) and the average score on the scale was 24.9 ( $\mathrm{sd} \pm 8.17)$. Among the activities present in the FES-I-BRASIL scale, the highest scores, representing greatest concern about falling, were: walking on a slippery surface, going up or down stairs, bathing, going up or down a slope, and walking on an uneven surface (Figure 2).

Table 1. Sociodemographic characteristics and health profile ( $\mathrm{n}=314)$. Juiz de Fora, Minas Gerais, 2015.

\begin{tabular}{|c|c|c|}
\hline Variable & $\begin{array}{l}\text { Presence of fear of falling. } \\
\mathrm{n}(\%)\end{array}$ & $\begin{array}{l}\text { Absence of fear of falling. } \\
\mathrm{n}(\%)\end{array}$ \\
\hline \multicolumn{3}{|l|}{ Sex } \\
\hline Male & 99 (33.1) & $7(46.7)$ \\
\hline Female & $200(66.9)$ & $8(53.3)$ \\
\hline \multicolumn{3}{|l|}{ Age (Years) } \\
\hline $60-70$ & $129(43.1)$ & $7(46.7)$ \\
\hline $71-80$ & $119(39.8)$ & $5(33.3)$ \\
\hline Over 80 & $51(17.1)$ & $3(20.0)$ \\
\hline \multicolumn{3}{|l|}{ Education (years) } \\
\hline Illiterate & $27(9.0)$ & $2(13.3)$ \\
\hline 1 to 4 & $188(62.9)$ & $7(46.7)$ \\
\hline 5 to 10 & $59(19.8)$ & $5(3.4)$ \\
\hline 11 or more & $25(8.4)$ & $1(6.7)$ \\
\hline \multicolumn{3}{|l|}{ Socio-economic level } \\
\hline A or B & $82(27.4)$ & $7(46.7)$ \\
\hline $\mathrm{C}$ & $177(59.2)$ & $7(46.7)$ \\
\hline $\mathrm{D}$ or $\mathrm{E}$ & $40(13.4)$ & $1(6.7)$ \\
\hline \multicolumn{3}{|l|}{ Marital status } \\
\hline Married or stable union & $170(56.9)$ & $6(40.0)$ \\
\hline Widowed & $93(31.1)$ & $6(40.0)$ \\
\hline Separated or divorced & $24(8.0)$ & $2(13.3)$ \\
\hline Single & $12(4.0)$ & $1(6.7)$ \\
\hline
\end{tabular}


Continuação da Tabela 1

\begin{tabular}{|c|c|c|}
\hline Variable & $\begin{array}{l}\text { Presence of fear of falling. } \\
\mathrm{n}(\%)\end{array}$ & $\begin{array}{l}\text { Absence of fear of falling. } \\
\mathrm{n}(\%)\end{array}$ \\
\hline \multicolumn{3}{|l|}{ Living arrangement } \\
\hline Live alone & $36(12.0)$ & $2(13.3)$ \\
\hline Reside with companion & $263(88)$ & $13(86.7)$ \\
\hline \multicolumn{3}{|l|}{ Self-perceived health } \\
\hline Excellent/very good/good & $168(56.2)$ & $10(66.7)$ \\
\hline Fair/poor & $131(43.8)$ & $5(33.3)$ \\
\hline \multicolumn{3}{|l|}{ Morbidity reported } \\
\hline Yes & $268(89.6)$ & $9(60.0)$ \\
\hline No & $31(10.4)$ & $6(40.0)$ \\
\hline \multicolumn{3}{|l|}{ Difficulty walking } \\
\hline No & $180(60.2)$ & $12(80.0)$ \\
\hline Yes & $119(39.8)$ & $3(20.0)$ \\
\hline \multicolumn{3}{|c|}{ Use of an assistive device for walking } \\
\hline No & $261(87.3)$ & $13(86.7)$ \\
\hline Human assistance & $15(5.0)$ & $1(6.7)$ \\
\hline Cane/crutches & $21(7.0)$ & $1(2.3)$ \\
\hline Walker & $2(0.7)$ & $0(0)$ \\
\hline \multicolumn{3}{|l|}{ Ongoing medication use } \\
\hline None & $23(7.7)$ & $3(20.0)$ \\
\hline 1 to 4 medications & $160(53.5)$ & $9(60.0)$ \\
\hline More than 4 medications & $116(38.8)$ & $3(20.0)$ \\
\hline \multicolumn{3}{|l|}{ Fall } \\
\hline No & $196(65.6)$ & $11(73.3)$ \\
\hline Yes & $103(34.4)$ & $4(26.7)$ \\
\hline \multicolumn{3}{|l|}{ Unified Health System user } \\
\hline Yes & $289(96.7)$ & $14(93.3)$ \\
\hline No & $10(3.3)$ & $1(6.7)$ \\
\hline \multicolumn{3}{|c|}{$\begin{array}{l}\text { Functional capacity for performing Instrumental } \\
\text { Activities of Daily Living Scale }\end{array}$} \\
\hline Independent & $280(93.6)$ & $15(100.0)$ \\
\hline Dependent & $19(6.4)$ & $0(0)$ \\
\hline
\end{tabular}

Source: Table prepared by authors 


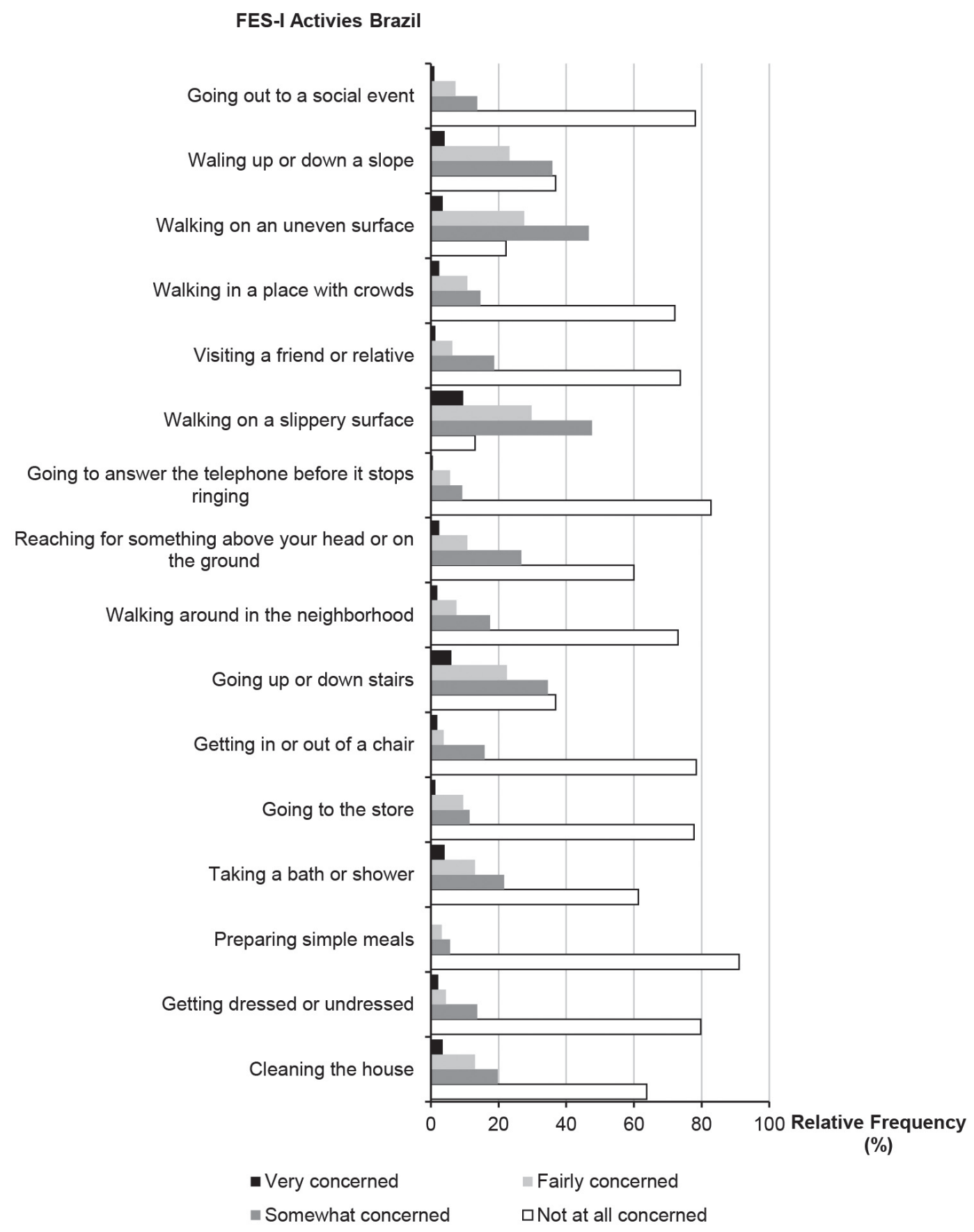

Figure 2. Concern reported by elderly persons on activities assessed in the Falls Efficacy Scale - International - Brazil. Juiz de Fora, Minas Gerais, 2015.

The Spearman correlation showed significant results $(p<0.05)$ between fear of falling and all the variables studied. There was a weak positive correlation between FES-I-BRASIL and selfperceived health $(\mathrm{r}=0.299)$, FES-I-BR ASIL and use of an assistive device for walking ( $\mathrm{r}=0.337)$, and FES-I-BRASIL and age ( $\mathrm{r}=0.199)$. There was also a weak negative correlation observed between FES-I-BR ASIL and history of falls ( $\mathrm{r}=-0.177)$, FES$I$-BR ASIL and difficulty walking $(\mathrm{r}=-0.480)$, and FES-I BRASIL and functional capacity $(\mathrm{r}=-0.476)$ (Table 2). 
Table 2. Correlation between fear of falling and the variables analyzed. Juiz de Fora, Minas Gerais, 2015.

\begin{tabular}{lll}
\hline Variable & $\mathrm{r}$ & $\mathrm{p}$ \\
\hline Age & 0.199 & $<0.01$ \\
\hline Self-perceived health & 0.299 & $<0.01$ \\
\hline Difficulty walking & -0.480 & $<0.01$ \\
\hline Use of an assistive device for walking & 0.337 & $<0.01$ \\
\hline History of falls & -0.177 & $<0.01$ \\
\hline Functional capacity for performing Instrumental Activities of Daily Living Scale & -0.476 & $<0.01$ \\
\hline
\end{tabular}

Note: $\mathrm{p}=$ Accurate significance level for the Spearman correlation coefficient

\section{DISCUSSION}

The prevalence of fear of falling in the study population was $95.2 \%$, similar to that found in other studies ${ }^{7,8,14}$. Lower prevalence values, from $19 \%$ to $78 \%$, were observed in other studies, however these variations can be attributed to the diversity of tools used to assess the outcome, differences in the characteristics of the population studied, and other methodological attributes ${ }^{4,15-19}$.

Considering that $65.9 \%$ of the elderly had not reported falls in the previous 12 months, it can be inferred that fear of falling was present independent of its actual occurrence. Studies show that fear of falling has been reported both by elderly persons who have experienced falls, as well as by those who have never fallen ${ }^{3,6,7}$. Among those who have fallen, literature suggests that these individuals consider themselves less able to avoid a fall and, consequently, would be more prone to suffer another. Low selfconfidence in avoiding falls can reduce the practice of activities due to fear of falling again, generating a functional decline due to inactivity, which would increase the risk of further falls ${ }^{2,49,16-18}$. Fear of falling proved to grow with increased age, corroborating other investigations ${ }^{4,9,17,18}$. With the aging process, older people tend to present a physical and functional decline due to lower functional reserve capacity. According to Lopes et al. ${ }^{7}$ this decline of functional reserve that occurs with advancing age alters the perception of the elderly regarding these falls, which can generate a sense of low self-efficacy and consequently, concern about falling.
A weak positive correlation was also observed between fear of falling and a negative self-perception of health. Self-perceived health has been shown to be a reliable method and a robust overall health indicator and predictor of morbidity, mortality, and physical decline in the elderly population. It can synthesize a complex interaction of factors involved in the health of the elderly ${ }^{20,21}$. A similar result was found in the study by Silva et al. ${ }^{22}$, which showed that among elderly participants in regular physical activity, those who rate their own health as poor tend to have higher scores on the FES-I-BRASIL, and consequently, a greater concern about falling than those who have a better perception of their health ${ }^{4,9,17,18}$.

Fear of falling proved more frequent in older people who have difficulty walking. It is likely that subjects who report difficulty walking already present a certain decline in functional capacity and changes in balance and gait. These changes impede the action of safe and effective walking and undermine the self-confidence of these individuals in avoiding falls, creating a basis for constructing their fear.

The use of an assistive device for walking showed an association among the elderly who reported concern about falling. The diminished muscle strength and flexibility, and the impairment of the somatosensory, vestibular, and sensory systems, resulting from the aging process, alter postural control and balance, and hinder the practice of walking effectively and safely ${ }^{3,23}$.

Studies point out that elderly people who report fear of falling use different strategies to maintain 
stability while walking. Smaller step length and height, greater support base, and more time in the double support phase trigger a reduction in walking speed and alter stability. Thus, the variability of the spatial and temporal parameters of walking by these elderly persons contribute to a more unsteady gait and an even higher risk of falls ${ }^{3,19,24-26}$. Again according to Lopes et $\mathrm{al}^{7}$, seniors with a fear of falling tend to employ the agonist and antagonist muscles simultaneously, resulting in postural rigidity, abnormal gait, poor postural strategies, and dependence on devices to guarantee stability. These assistive devices enable functional independence and offer safety and confidence to the elderly, making it easier for them to carry out their daily activities. However, when not indicated or when used inappropriately, they can have the opposite effect and contribute to unsafe locomotion, forming an instrument capable of causing falls ${ }^{23,27-29}$.

The correlation found between fear of falling and functional capacity indicates that functional dependence is associated with increased fear of falling. Literature reports that older adults with functional decline tend to present low self-efficacy in carrying out daily activities, since they have lower physical and functional performance, and often report fear of falling during their execution. It also reports that elderly persons who restrict their activities due to fear of falling are more prone to sedentary living and social isolation, resulting in a loss of functional capacity and consequently, a fear of falling, creating and perpetuating a vicious cycle of adverse effects $3,6,22,30,31$.

Going up or down stairs, bathing, walking on an uneven surface, going up and down a slope, and walking on a slippery surface were the highestscore activities in the FES-I-BRASIL, similar to the findings in other studies ${ }^{7,14}$. Activities such as these pose challenges for elderly people due to the heavy demands placed on the osteomyoarticular system and other components responsible for maintaining dynamic equilibrium. It is noted that due to fear, the elderly tend to have diminished self-confidence about their abilities and thus avoid exposure to threatening situations they consider a risk for falling, by restricting their activities, thus perpetuating a cycle of adverse health effects for these same individuals ${ }^{2,9}$. A study by Dias et al. ${ }^{15}$ reveals that older people who restrict their activities due to fear of falling present lower self-efficacy in avoiding falls, are slower at walking, have more illnesses, poorer self-perceived health, and perform worse in the IADLs.

For Camargos et al. ${ }^{5}$, external activities involving social participation are one of the main causes of concern about falling among the elderly in the community. The level of information processing required for controlling balance and maintaining stability is significantly higher in the community environment ${ }^{32}$.

However, the home environment can also present situations that pose a greater need for balance and postural control, as is the case for the elderly who reported being worried about falling while bathing and walking on slippery surfaces. Several studies have shown that the most frequent site where falls occur was inside the elderly person's own home, especially the bedroom and bathroom ${ }^{14,23,29,30}$. Oliveira et al. ${ }^{31}$ showed a tendency for increased falls outdoors. For these authors, intrinsic factors are related to the place where falls occur. Elderly people with intact physical capacity tend to fall in outside environments, while those with functional impairment tend to suffer falls within their own homes. This situation calls attention to the risk of social isolation and acquiring sedentary lifestyles due to physical inactivity resulting from the presence of fear of falling ${ }^{15,16,33}$.

Among the study's limitations, the possibility of memory bias is noted, due to participant selfreporting in surveying the variables of interest, which may have influenced the data. However, household population-based surveys with elderly persons living in the community are extremely important because they are configured as relevant tools for analysis and assessment in health, monitoring, and the management of collective practices. They are potentially useful tools that can offer assistance in implementing public policies and conducting future research that investigates the study theme more thoroughly.

\section{CONCLUSION}

This study identified a high prevalence of fear of falling in elderly persons in the community 
and significant correlation between the outcome and self-perceived health, difficulty walking, use of an assistive device for walking, age, history of falls, and functional capacity. Among the activities that most concern the elderly regarding fear of falling, the highest scoring activities were: bathing, going up or down stairs, walking on an uneven surface, going up or down a slope, and walking on a slippery surface.

\section{REFERENCES}

1. World Health Organization. World report on ageing and health. Geneva: WHO; 2015.

2. Antes DL, Schneider IJC, Benedetti TRB, D'Orsi E. Medo de queda recorrente e fatores associados em idosos de Florianópolis, Santa Catarina, Brasil. Cad Saúde Pública. 2013;29(4):758-68.

3. Moreira MA, Oliveira BS, Moura KQ, Tapajós DM, Maciel ACC. A velocidade da marcha pode identificar idosos com medo de cair? Rev Bras Geriat Gerontol. 2013;16(1):71-80.

4. Zijlstra GA, Van Haastregt JC, Van Eijk JT, Van Rossum E, Stalenhoef PA, Kempen GI. Prevalence and correlates of fear of falling, and associated avoidance of activity in the general population of community-living older people. Age Ageing. 2007;36(3):304-9.

5. Camargos FFO, Dias RC, Dias JMD, Freire MTF. Adaptação transcultural e avaliação das propriedades psicométricas da Falls Efficacy Scale - Internacional em idosos brasileiros (FESI-Brasil). Rev Bras Fisioter. 2010;14(3):237-43.

6. Legters K. Fear of falling. Phys Ther. 2002;82(3):264-72.

7. Lopes KT, Costa DF, Santos LF, Castro DP, Bastone AC. Prevalência do medo de cair em uma população de idosos da comunidade e sua correlação com mobilidade, equilíbrio dinâmico, risco e histórico de quedas. Rev Bras Fisioter. 2009;13(3):223-9.

8. Pimentel I, Scheicher ME. Comparação da mobilidade, força muscular e medo de cair em idosas caidoras e não caidoras. Rev Bras Geriatr Gerontol. 2013;16(2):251-7.

9. Scheffer AC, Schuurmans MJ, Van Dijk N, Van der Hooft T, Rooij SE. Fear of falling: measurement strategy, prevalence, risk factors and consequences among older persons. Age Ageing. 2008;37(1):19-24
We believe that the high prevalence of fear of falling in the elderly population, within a scenario of increasing population aging, dictates the need to understand this phenomenon as a public health problem, and presses for the development and adoption of new healthcare strategies and actions for rehabilitation, prevention, and health promotion, which will contribute to the quality of life of this population and help ensure their healthy aging.

10. Brasil. Ministério da Saúde, Secretaria de Atenção à Saúde, Departamento de Atenção Básica.

Envelhecimento e saúde da pessoa idosa. Brasília, DF: MS; 2006.

11. Rahman MM, Davis DN. Addressing the class imbalance problem in medical datasets. IJMLC. 2013;3(2):224-8.

12. Camargos FFO. Adaptação transcultural e avaliação das propriedades psicométricas da falls efficacy scaleinternational: um instrumento para avaliar medo de cair em idosos [dissertação]. Belo Horizonte: Universidade Federal de Minas Gerais, Escola de Educação Física, Fisioterapia e Terapia Ocupacional; 2007.

13. Lawton MP, Brody EM. Assessment of older people: self-maintaining and instrumental activities of daily living. Gerontologist. 1969;9(3):179-86.

14. Fucahori FS, Lopes AR, Correia JJA, Silva CKD, Trelha CS. Fear of falling and activity restriction in older adults from the urban community of Londrina: a cross-sectional study. Fisioter Mov. 2014;27(3):379-87.

15. Dias RC, Freire MTF, Santos EGS, Vieira RA, Dias JMD, Perracini MR. Características associadas às restrições de atividades por medo de cair em idosos comunitários. Rev Bras Fisioter. 2011;15(5):406-13.

16. Gaxatte C, Nquyen T, Chourabi F, Salleron J, Pardessus V, Delabrière I, et al. Fear of falling as seen in the multidisciplinary falls consultation. Ann Phys Rehabil Med. 2011;54(4):248-58.

17. Kempen GI, Haastregt JC, McKee KJ, Delbaere $\mathrm{K}$, Zijlstra GA. Socio-demographic, health-related and psychosocial correlates of fear of falling and avoidance of activity in community-living older persons who avoid activity due to fear of falling. BMC Public Health. 2009;9(1):1-16. 
18. Kumar A, Carpenter H, Morris R, Iliffe S, Kendrick D. Which factors are associated with fear of falling in community-dwelling older people? Age Ageing. 2014;43(1):76-84.

19. Rochat S, Büla CJ, Martin E, Seematter-Bagnoud L, Karmaniola A, Aminian K, et al. What is the relationship between fear of falling and gait in wellfunctioning older persons aged 65 to 70 years? Arch Phys Med Rehabil. 2010;91(6):879-84.

20. Confortin SC, Giehl MWC, Antes DL, Schneider IJC, D’Orsi E. Autopercepção positiva de saúde em idosos: estudo populacional no Sul do Brasil. Cad. Saúde Pública. 2015;31(5):1049-60.

21. Silva PA. Determinantes individuais e sociais do estado de saúde subjetivo e de bem-estar da população sênior de Portugal. Cad Saúde Pública. 2014;30(11):2387-2400.

22. Silva CK, Trelha CS, Silva Junior RA. Fear of falling and self-perception of health in older participants and nonparticipants of physical activity programs. Motriz. 2013;19(4):763-9.

23. Cruz DT, Ribeiro LC, Vieira MT, Teixeira MTB, Bastos RR, Leite ICG. Prevalência de quedas e fatores associados em idosos. Rev Saúde Pública 2012;46(1):138-46.

24. Ayoubi F, Launay CP, Annweiler C, Beauchet O. Fear of falling and gait variability in older adults: a systematic review and meta-analysis. J Am Med Dir Assoc. 2015;16(1):14-9.

25. Davis JR, Campbell AD, Adkin AL, Carpenter MG. The relationship between fear of falling and human postural control. Gait Posture. 2009;29(2):275-9.
26. Kirkwood RN, Moreira BS, Vallone MLDC, Mingoti AS, Dias RC, Sampaio RF. Step length appears to be astrong discriminant gait parameter for elderly females highly concerned about falls: a cross-sectional observational study. Physiotherapy 2011;97(2):126-31.

27. Klima DW, Newton RA, Keshner EA, Davey A. Fear of falling and balance ability in older men: the priest study. J Aging Phys Act 2013;21(4):375-86.

28. Menezes RL, Bachion MM. Estudo da presença de fatores de riscos intrínsecos para quedas, em idosos institucionalizados. Cienc Saúde Coletiva. 2008;13(4):1209-18.

29. Rodrigues IG, Fraga GP, Barros MBA. Quedas em idosos: fatores associados em estudo de base populacional. Rev Bras Epidemiol. 2014;17(3):705-18.

30. Antes DL, D'Orsi E, Benedetti TRB. Circunstâncias e consequências das quedas em idosos de Florianópolis. Epi Floripa Idoso 2009. Rev Bras Epidemiol. 2013;16(2):469-81.

31. Oliveira AS, Trevizan PF, Bestetti MLT, Melo RC. Fatores ambientais e risco de quedas em idosos: revisão sistemática. Rev Bras Geriatr Gerontol. 2014;17(3):637-45.

32. Deshpande N, Metter EJ, Lauretani F, Bandinelli S, Ferrucci L. Interpreting fear of falling in the elderly: What do we need to consider? J Geriatr Phys Ther. 2009;32(3):91-6.

33. Deshpande N, Metter EJ, Lauretani F, Bandinelli S, Guralnik J, Ferrucci L. Activity restriction induced by fear of falling and objective and subjective measures of physical function: a prospective cohort study. J Am Geriatr Soc. 2008;56(4):615-20. 